$1-1-2014$

\title{
Climate Change Mitigation and the Global Energy System
}

Frank A. Felder

Follow this and additional works at: https://digitalcommons.law.villanova.edu/elj

Part of the Environmental Law Commons

\section{Recommended Citation}

Frank A. Felder, Climate Change Mitigation and the Global Energy System, 25 Vill. Envtl. L.J. 89 (2014). Available at: https://digitalcommons.law.villanova.edu/elj/vol25/iss1/3

This Article is brought to you for free and open access by Villanova University Charles Widger School of Law Digital Repository. It has been accepted for inclusion in Villanova Environmental Law Journal by an authorized editor of Villanova University Charles Widger School of Law Digital Repository. 


\title{
CLIMATE CHANGE MITIGATION AND THE GLOBAL ENERGY SYSTEM
}

\author{
Frank A. Felder*
}

To be successful, climate change mitigation policy must account for the global energy system (GES), which is a complex, large-scale, integrated, open, and socio-technical (CLIOS) system with long-lived, sunk (irreversible) assets that are subject to the interactions of consumers, producers, and politicians with economic and political incentives, and protracted public processes spanning multiple governmental jurisdictions. These structural elements result in several generic issues that climate change mitigation policies need to address to be effective, such as scalability, inertia, unanticipated outcomes, and the need to integrate political, economic, and technical factors.

\section{Introduction and Current State of Climate Mitigation Policy}

Global climate change mitigation policy is at a near standstill. There seems to be no near-term prospect of meaningful global action to stabilize greenhouse gas concentrations at levels that avoid harmful increases in global average temperatures and associated climate changes and negative impacts. This current state of affairs has triggered a great deal of scholarly work on the question of how to move forward. ${ }^{1}$

The fact that global climate change mitigation policy (mitigation) is stalled has been widely proclaimed. Major business as usual forecasts of the long-term future global energy picture indicate that the world will fall short of achieving climate mitigation goals, as

* Associate Research Professor and Director of the Center for Energy, Economic and Environmental Policy, Edward J. Bloustein School of Planning and Public Policy, Rutgers University. Professor Felder conducts research on energy policy, electricity markets, evaluations of energy efficiency and renewable resources, and the effects of climate change on electric power systems. He earned a B.S. and B.A. from the School of Engineering and Applied Sciences and Columbia College at Columbia University, a S.M. in Technology and Policy, and Ph.D. in Technology, Management and Policy at the Massachusetts Institute of Technology.

1. See Harvard Project on Climate Agreements, Belfer CTr. For SCI. \& INT'L Af. FAIRS, http://belfercenter.ksg.harvard.edu/project/56/harvard_project_on_ climate_agreements.html (last visited Nov. 10, 2013) (collecting scholarly works devoted to climate change). 
discussed by Felder, Andrews, and Hulkower. ${ }^{2}$ The International Energy Agency (IEA) concluded in 2012, "Taking all new developments and policies into account, the world is still failing to put the global energy system onto a more sustainable path." ${ }^{3}$ The IEA continued, "Global energy demand increases by over one-third in the period 2035. Energy-related $\mathrm{CO}_{2}$ emissions rise from an estimated $31.2 \mathrm{Gt}$ (giga tons) in 2011 to $37.0 \mathrm{Gt}$ in 2035 , pointing to a longterm average temperature increase of $3.6^{\circ} \mathrm{C} .{ }^{\prime} 4$ The New York Times summarized the 2012 meeting of the United Nations Framework Convention on Climate Change (UNFCCC) as follows: "Delegates from more than 190 nations agreed to extend the increasingly ineffective Kyoto Protocol a few years and to commit to more ambitious - but unspecified - actions to reduce emissions of climatealtering gases." 5 The report continued, "The Doha meeting did not produce even the barest outline of what that new agreement [that would replace the Kyoto Protocol] would look like, leaving those questions for future meetings." 6

According to Joseph Aldy and Robert Stavins, "A way forward is needed for the post-2012 period to address the threat of global climate change." 7 The authors continue with an evaluation of the weaknesses of the Kyoto Protocol:

First, some of the largest emitters are not constrained by Kyoto. The Protocol has not been ratified by the United States, and it does not include emissions targets for some of the largest and most rapidly growing economies in the

2. See Frank Felder, Clinton J. Andrews, \& Seth D. Hulkower, Which Energy Future?, in Energy Sustainability and the Environment: Technology, Incentives, Behavior 31-62 (Fereidoon P. Sioshansi ed., Elsevier Press 2011) (discussing business projections of climate change mitigation plans).

3. World Energy Outlook 2012 Factsheet, INT'L ENERGY AGENCY, 1 (2012), available at http://www.worldenergyoutlook.org/media/weowebsite/2012/factsheets.pdf (noting fossil fuels remain dominant source of energy).

4. Id. (concluding lower rates of world-wide economic growth would have minimal impacts on current energy and climate patterns).

5. John M. Broder, Climate Talks Yield Commitment to Ambitious, but Unclear, Actions, N.Y. Times (Dec. 8, 2012), http://www.nytimes.com/2012/12/09/science/ earth/talks-on-climate-produce-promises-and-complaints.html (documenting struggles in various plans aimed at cutting greenhouse gases).

6. Id. (focusing on lack of detailed plans aimed at replacing Kyoto).

7. Joseph E. Aldy \& Robert N. Stavins, Framework Convention on Climate Change, Designing the Post-Kyoto Climate Regime: Lessons from the Harvard Project on International Climate Agreements. An Interim Progress Report FOR THE 14TH CONFEREnce OF THE PARTIEs xi (2008), available at http:// belfercenter.ksg.harvard.edu/files/Interim\%20Report\%20081203\%20Akiko\%20 v6.pdf (claiming broad-based consensus on any successor to Kyoto is needed to be effective). 
developing world. Second, a relatively small number of countries are asked to take action, which has resulted in concerns about emissions leakage and competitiveness. Third, the nature of the Protocol's emissions trading elements has caused concern. The provision in Article 17 for international emissions trading among nation-states is unlikely to be effective, if it is utilized at all. And the Clean Development Mechanism (CDM) is plagued by criticisms that it is crediting projects that would have happened anyway (commonly known as the problem of "additionality"). Fourth, the Kyoto Protocol-with its five year time horizon (2008 to 2012) -represents a relatively short-term approach for what is fundamentally a long-term problem. Finally, the agreement may not provide sufficient incentives for compliance. ${ }^{8}$

The first step forward is defining the criteria by which any mitigation proposal should be assessed, such as how "scientifically sound, economically rational, and politically pragmatic" it is. ${ }^{9}$ Specifically:

By "scientifically sound" we mean an international agreement that is consistent with achieving the objective of stabilizing atmospheric concentrations of greenhouse gases at levels that avoid dangerous anthropogenic interference with the global climate. By "economically rational" we mean pursuing an approach or set of approaches that are likely to achieve global targets at minimum cost-that is, cost effectively. And by "politically pragmatic" we mean a post-Kyoto regime that is likely to bring on board the United States and engage key, rapidly-growing developing countries in increasingly meaningful ways over time. ${ }^{10}$

Proposals attempting to meet these three criteria stretch across a continuum of possible policy architectures starting from top-down approaches ("centralized international agreement" with targets and timetables), to harmonizing national policies such as carbon taxes, to bottom-up policies that coordinate unilateral national policies. ${ }^{11}$

8. Id. (enumerating weaknesses of Kyoto Protocol).

9. Id. at 1 (noting history of Harvard Project on International Climate Agreements).

10. Id. (defining "scientifically sound," "economically rational," and "politically pragmatic").

11. See id. at 5-6 (discussing different alternative policy architectures for PostKyoto period). 
The question then becomes which policy architecture (targets and timetables, harmonized domestic policies, or coordinated and unilateral national policies) best meets these three criteria, which requires exploring policy alternatives within each archetype. Policies that satisfy these three criteria will be called effective.

To answer the next level of questions, a sufficiently robust yet tractable framework is needed to provide a context in which to assess various mitigation and adaptation options. Perhaps given the complexity of the problem, multiple frameworks should be employed in order to ferret out issues, define problem statements, and analyze solutions. The use of an appropriate framework itself is subject to debate. For instance, some scholars claim that the feasibility constraint of International Paretianism - meaning all states that join such a treaty are equally strengthened and not made worse off - must be part of any analytical construct instead of, for example, a criterion or constraint related to climate justice, ${ }^{12}$ whereas others put notions of justice front and center in any analysis. ${ }^{13}$

This paper argues that the concept of the GES is a useful framework, albeit not necessarily the only one, to assist in working through many of the difficult issues associated with effective mitigation policies. This framework is not a model that generates solutions to the very difficult problem of formulating a successful internationally agreeable mitigation policy. Instead, its goal is to provide guidance and insights to facilitate arriving at feasible solutions, if they exist. This paper revises and updates earlier work regarding the GES, as discussed by Felder, and develops the GES framework in the context of mitigating greenhouse gas emissions to achieve an acceptable stable concentration of greenhouse gases. ${ }^{14}$

\section{The Essential Elements of the Global Energy System}

An early use of the term GES occurred in 1977 by Häfele and Sassin who traced the development of the GES over time. Their findings emphasize the importance of "severe soft problems" such

12. Eric A. Posner \& David A. Weisbach, International Paretianism: A Defense, in Harvard Project on Climate Agreements 2012, available at http://belfercenter .hks.harvard.edu/files/posner-weisbach_dp52.pdf (discussing International Paretianism).

13. See Edward A. Page, Climate Change, Justice and Future Generations 50 (Edward Elgar Pub. 2007) (noting role of justice in climate change analysis).

14. See Frank Felder, A Framework for Evaluation of Energy Policy Proposals, in IEeE Energy 2030 Conference Proceedings, 485, 485-92 (2008) [hereinafter $A$ Framework for Evaluation of Energy Policy Proposals]. 
as "complex management and decision-making." 15 Others have talked about subsystems of the GES as a system; for instance Sagar and Holdren refer to the global energy innovation system as part of what they refer to as the "energy sector or energy system."16 More recently, one scholar has used the term "energy and industrial systems" and "energy-economic system" in discussing climate change mitigation policies. ${ }^{17}$

Coincident with the needs of policymakers to reevaluate global climate change mitigation policy, the importance of a multi-disciplinary approach to solving intractable social problems has long been recognized. ${ }^{18}$ These problems consist of intertwined technological and social complexities that cannot be adequately addressed by a reductionist scientific approach. Analyzing these complex problems requires a multidisciplinary, interdisciplinary, and transdisciplinary effort that incorporates soft elements such as human behaviors and social elements, accounts for political environments that are likely to be subject to substantial, unpredictable, and frequent changes, including changes in objectives, and effectively serves participants and stakeholders. ${ }^{19}$ A system consists of interconnected components and has emergent properties, properties that are possessed by the system but not by its parts. One specific system's approach is the CLIOS framework, which has been applied to other complex systems, such as transportation ${ }^{20}$ and energy. ${ }^{21}$

Climate change affects the GES, and the success of climate change policies depends on how they affect the GES. Specifically, for mitigation polices to be effective, they must alter the physical

15. Wolf Häfele \& Wolfgang Sassin, The Global Energy System, 2 ANN. ENERGY REv. 1, 29 (1977) (describing progression of GES).

16. See Ambuj D. Sagar \& John P. Holdren, Assessing the Global Energy Innovation System: Some Key Issues, 30 Energy PoL'y 465, 465-69 (2002).

17. See generally Adam B. Jaffe, Technology Policy and Climate Change, 3 Climate Change Econ. 1250025-1 (2012) [hereinafter Technology Policy and Climate Change] (finding that it is important to respond to climate change in "cost-effective" manner).

18. See Peter Checkland, Soft Systems Methodology: A Thirty Year Retrospective, 17 Systems Res. \& BeHAV. SCI. S11 (2000), available at http://mail.im.tku.edu.tw/ my day/teaching/992/SMS/S/992SMS_T3_Paper_20110326_soft_systems_methodo logy_retrospective_checkland_2000.pdf (describing efficacy of multi-disciplinary approach).

19. See Maurice W. Kirby, The Intellectual Journey of Russell Ackoff: From OR Apostle to OR Apostate, 54 J. Operational Res. Soc'v, 1127, 1127-40 (2003) (discussing Ackoff's rejection of mathematical systems of operational systems for wider social and political approaches).

20. See Joseph M. Sussman, Perspectives on Intelligent Transportation Systems (Springer 2005).

21. See A Framework for Evaluation of Energy Policy Proposals, supra note 14, at $485-92$. 
world in ways that would not have occurred without the policies. Policies that could have such an impact on the physical world include a carbon-free technological mandate for new energy sources, a change in the economic system, for example by implementing a carbon tax, or the creation of a new political institution, such as an international treaty. Thus, the GES framework, if it is to be useful, must encompass the multiple levels of technology, economics, and politics. Of course, mitigation proposals are made and, if implemented, operate within a particular context. The GES contains several important structural features discussed below that mitigation proposals should address if they are to be successful. The following discussion of particular elements of the GES is not exclusive and is not meant to suggest that each item is of equal importance for every type of context and mitigation proposal. Nonetheless, it attempts to capture the GES's essential CLIOS features in the context of climate change.

\section{A. The Global Energy System is Extremely Large in Scale}

Energy projects are large-scale in cost, physical size, lifetimes, and impacts. According to the World Energy Outlook, "Large-scale investment in energy-supply infrastructure is required to replace existing supply capacity and expand to meet growing energy needs. In the New Policies Scenario, cumulative investment of $\$ 37$ trillion is needed in the world's energy supply system over 2012-2035, equivalent to $1.5 \%$ of global GDP on average during that period."22 Regarding the electric power sector,

A total of $5890 \mathrm{GW}$ (gigawatts) of capacity additions more than the total installed capacity of the whole world in 2011 - is required over the Outlook period. One-third of this is to replace retiring plants; the rest is to meet growing electricity demand. Renewables represent half the capacity additions, at $3000 \mathrm{GW}$ over the period 2012-35, followed by [natural] gas at $1400 \mathrm{GW}$. The total power sector requires investment over 2012-35 of $\$ 16.9$ trillion, almost half the total energy supply infrastructure investment in this period. Two-fifths of this investment is for electricity networks, while the rest is for generation capacity. Of the investment in generation capacity, more than

22. World Energy Outlook 2012 Factsheet, supra note 3, at 2 (explaining investment necessary to meet energy \demand from 2012-2035). 
$60 \%$ is for renewables - principally wind $(22 \%)$, hydro $(16 \%)$, and solar PV (13\%). ${ }^{23}$

The GES spans the earth and crosses multiple national and sub-national political boundaries. Oil, natural gas, coal, and uranium are shipped across the globe, and electricity is transmitted hundreds to approximately a thousand miles across multiple states and countries. Energy investments are long-lived assets, spanning decades, if not longer. For example, in the case of a U.S. nuclear waste disposal site for commercially spent fuel, the site must prevent the release of radionuclides to the accessible environment for at least one thousand years. ${ }^{24}$ U.S. nuclear power plants are initially licensed for forty years, and the U.S. Nuclear Regulatory Commission (NRC) may extend their licenses for an additional twenty years. Research is underway to enable nuclear power plants to last eighty years. Other types of power plants, refineries, pipelines, and production facilities have similar operating lives, although they can be expanded, upgraded, and revised over the course of their multiple decades of life. On the consumption side, buildings last on the order of a century. The shortest duration products are probably automobiles and consumer appliances, such as refrigerators, stoves, hot water heaters, air conditioners, and similar consumer products, which last five to fifteen years.

The GES has large-scale impacts. The obvious, but not the only example, is climate change. Changes in the price of oil reverberate almost instantly throughout the global economy and this may soon be the case with natural gas, as LNG transportation increases the transition of natural gas from a continental to a global market. Similarly, atmospheric emissions, including greenhouse gases, affect the globe and multi-national regions. Even within a country, the impacts of air pollution can be devastating. For example, recent air pollution levels in Beijing, China were literally off the charts. ${ }^{25}$

The large-scale nature of the GES has immediate implications for mitigation policies. These policies must span the globe, cover all the uses of energy, including transportation, electricity, and heating, and be able to fund the tremendous amount of investment

23. Id. at 3 (outlining statistics about electric power sector).

24. Cong. Research Serv., IB92059, Civilian Nuclear Waste Disposal (2002), available at http://cnie.org/NLE/CRSreports/waste/waste-2.cfm (discussing problems of nuclear energy's waste).

25. Blackest Day, Economist (Jan. 14, 2013, 4:49 PM), http://www.economist .com/blogs/analects/2013/01/beijings-air-pollution (noting issues Beijing, China faces due to air pollution). 
needed to replace and expand the existing GES. Mitigation policies that are designed to stábilize greenhouse gas concentrations must reduce greenhouse gas emissions to levels that are currently being removed by nature and humans. This requires a drastic reduction in greenhouse gas emissions, perhaps more than sixty percent. ${ }^{26}$ Further, if this stabilization is to limit global average temperature increases, it must be done in a relatively short period of time, perhaps several decades or less. Since fossil fuels are the dominant energy source for all major uses of energy, achieving relatively near-term stabilization in effect requires a complete overhaul of the existing and proposed GES. For example, in the United States, the transportation sector is almost entirely oil based, the electric power sector is about seventy percent coal and natural gas, and the heating sector is almost one hundred percent oil and natural gas. ${ }^{27}$

Moreover, although most greenhouse gases are emitted as a result of energy production and consumption, either the non-energy sources of greenhouse gases also must be substantially reduced, or energy-related greenhouse gases must be reduced further to compensate for the corresponding lack of reduction in non-energy greenhouse gases. Adding to this difficult task is the problem that there is no single scalable carbon-free technology that can be deployed to achieve relatively near-term and perhaps even longterm stabilization goals. ${ }^{28}$

\section{B. Jurisdictional and Boundary Issues}

Due to the large-scale nature of the GES, it crosses many jurisdictional boundaries. There are approximately 190 countries, all affected to various degrees, by international oil markets, global climate change, natural gas transportation, electric power systems, and other subsystems and components of the GES. In the case of the United States, with its federal system, there are local (including villages, towns, and counties), state, and national governments with different roles and responsibilities with respect to energy planning

26. Technology Policy and Climate Change, supra note 17, at 1250025-3 (noting greenhouse gas levels should be lowered in order to stabilize climate); H. Damon Matthews \& Ken Caldeira, Stabilizing Climate Requires Near-Zero Emissions, 35 GEOPHYSICAL RES. LETTERS L04705 (2008) (outlining effects of different levels of carbon dioxide emissions in same 500 year period).

27. Total Energy, U.S. EnERGy Info. AGENCY, http://www.eia.gov/totalenergy/ (last visited Aug. 20, 2013) (analyzing major sources of energy in U.S.).

28. See generally Technology Policy and Climate Change, supra note 17 (noting need for technology that provides climate stabilization in near-future). 
and policies. Because the costs and benefits of specific energy investments and operations are not uniform, different jurisdictions have different views. For example, the state of Maine may oppose building a transmission line from Maine to Boston, Massachusetts because it would raise electricity prices in Maine and negatively affect land usage and value, whereas those in Boston may support the line for its reliability and economic benefits.

These jurisdictional disputes are not limited only to current governments. The GES spans long swaths of time as well as geography. One can think of a future government as another "jurisdiction" that may have a different view of what today's government decides. In addition, within a given jurisdiction and government, there may be disputes between agencies or branches of the government.

The inter-jurisdictional nature of mitigation policy inevitably slows down changes to the GES as multiple jurisdictions must try to resolve their differences. Attempts at meaningful international climate policy demonstrate this point. In some cases, there is an overarching governmental entity, for example the U.S. federal government, which can, under certain circumstances, step in and resolve jurisdictional disputes. Staying with the U.S. example, the siting of natural gas pipelines is basically a federally-driven process with state and local input that proceeds in an orderly manner. This is in sharp contrast to siting transmission lines, which is dictated by localities and states. Although U.S. federal authority has increased in this area recently, it remains to be seen if it can resolve these seemingly intractable inter-state siting issues. In issues that cross national jurisdictional boundaries, there is no higher authority that can resolve them unless the nations themselves agree to such a structure. Forming such a structure and having it operate is in itself time-consuming, as the experience since the signing of the Kyoto Treaty has shown.

\section{The Global Energy System is Complex and Uncertain}

The GES has manifold complexity. Borrowing from the CLIOS literature, ${ }^{29}$ the GES is structurally complex because it contains a large number of interconnected parts: it exhibits behavioral

29. See generally Joseph M. Sussman, The "CliOS Process": A User's Guide (2007), available at http://ocw.mit.edu/courses/engineering-systems-division/esd04j-frameworks-and-models-in-engineering-systems-engineering-system-designspring-2007/readings/clios_process.pdf [hereinafter CLIOS PROCEss] (discussing complexity of GES). 
complexity because predictions of system behavior and outputs are hard, it contains nested complexity between the physical and technical components and the economic and political institutions that interact and govern parts of the GES, and it also has evaluative complexity because the users of the GES are multiple stakeholders that evaluate system performance in very different and even opposing ways.

Take one important subsystem of the GES: the electric power sector. Connected to this subsystem are additional subsystems of varying degrees of complexity, such as nuclear generation units, transmission lines, and distribution subsystems. One indication of the sector's complexity is illustrated by the blackout that occurred in the Eastern Interconnection on August 14, 2003, that affected Ontario, Canada, and parts of the United States, despite the enormous effort made to operate the grid reliably. ${ }^{30}$ Another example is the series of nuclear reactor accidents that occurred in Fukushima, Japan starting on March 11, 2011.

Complexity and uncertainty are related: complexity causes uncertainty, but is also caused by uncertainty. Some of these uncertainties are epistemic (i.e., the uncertainty itself is uncertain), not just aleatory (i.e., the uncertainty is well defined, such as the probabilities associated with rolling a die). Uncertainty exists regarding the current GES and increases dramatically when trying to predict what would happen under various mitigation proposals over long periods of time. Global climate change illustrates numerous uncertainties, their ranges, and implications. ${ }^{31}$ The uncertainties include the magnitude, impacts, costs, and ability of different policies to address global climate change. In some cases, the ranges of uncertainties are quantified, such as the likely range of temperature changes under different scenarios; in other cases, uncertainties are identified but not quantified, such as the effects of ocean acidification. Appropriate treatment of uncertainty without overwhelming the analysis is a difficult and open question.

The world's climate and the GES contain many positive feedbacks, which can be undesirable because they can lead to runaway systems behavior, and negative feedbacks, which can be desirable

30. Paul Hines, Jay Apt, \& Sarosh Talukdar, Large Blackouts in North America: Historical Trends and Policy Implications, 37 ENERGY POL'y 5249, 5249-59 (2009) (discussing electric power sector's complexity).

31. See Intergovernmental Panel on Climate Change, Climate Change 2007: Sinthesis Report, Summary for Policymakers (2007), available at http:// www.ipcc.ch/pdf/assessment-report/ar4/syr/ar4_syr_spm.pdf (highlighting uncertainties regarding climate change). 
because they stabilize system behavior, that further complicate predicting system behavior. Within the climate system, some important examples of feedback are clouds, the ice albedo, hydrological cycle, and water vapor. ${ }^{32}$ In the GES, energy prices are a major source of negative feedback; as prices increase, new production areas and technologies are pursued and demand decreases, driving the GES into equilibrium. This can lead to unanticipated consequences in the context of mitigation. Low U.S. natural gas prices have reduced the use of coal to produce electricity, reducing the price of coal, which has led to exporting coal to Europe. The net impact on global greenhouse gas emissions is not clear, in part, because European Union's greenhouse gas cap-and-trade policies would have to be considered.

The importance of energy prices, both in anticipating future energy production and consumption and as a mechanism to implement mitigation policies, cannot be overstated. Energy prices pervade the GES and inform the decisions of the world's population and the millions of businesses and organizations that use and produce energy. The pricing mechanisms that policymakers use to implement and fund mitigation policies also affect their success. ${ }^{33}$ For instance, if the cost of solar power becomes slightly less than the cost of natural gas-fired generation, the price of natural gas will decrease because less of it will be used to produce electricity, all else being equal. With the lower cost of natural gas, other uses of natural gas will increase, including some rebound in electricity consumption.

The complexity of the GES is exacerbated by the interplay between uncertainty and sunk costs. Much, if not all, of the initial investment in energy assets are sunk, that is, irreversible. Once a hydroelectric, nuclear, coal, or natural gas fired unit is built, it cannot be converted into another type of asset or moved. (A gas turbine can be converted to a combine cycle unit, however.) This is in sharp contrast to other investments, such as an airplane, which can obviously be moved or converted from a passenger to a cargo plane, or to a computer that can be used commercially for a business such as a flower shop, or individually, such as by a student.

32. See generally David Archer, Global Warming: Understanding the ForeCAST (John Wiley \& Sons, ltd., 2nd ed. 2012) (examining climate system feedback examples).

33. Frank Felder, Examining Electricity Price Suppression Due to Renewable Resources and Other Grid Investments, 24 Electr. J. 34, 34-46 (May 2011) (analyzing interconnectivity of energy prices and policymakers' pricing mechanisms). 
Making a new investment when the future is uncertain is risky and therefore costly. Prior to making a sunk investment under uncertainty, it may be more economic to delay the investment beyond the start date that a standard net present value (NPV) analysis would conclude because NPV analysis does not account for the cost of the option to delay. ${ }^{34}$ Correspondingly, investments that are flexible and can respond to changes in future conditions have an additional value that standard NPV analysis does not capture. Once the investment has been made, however, the asset is economic to operate so long as it recovers its going-forward costs, which can be small. So even if a new technology has a lower total cost than an existing technology's total cost, the new technology will not replace (without governmental intervention) existing assets unless its total costs are less than the existing technology's going-forward costs. These going-forward costs will typically arise in the future, perhaps slowly, as the asset depreciates and requires more ongoing costs to maintain its operations.

The combination of sunk investments, uncertainty, and some project flexibility gives rise to identifying, quantifying, and executing real options. Energy projects (and therefore mitigation policies) display several sources of flexibility, including project development activities, modularity, flexible designs, and operations, and involve both compound and parallel options. ${ }^{35}$ Determining the amount of flexibility that is optimal in individual energy projects is a challenging issue, but provides an opportunity to address uncertainty and improve energy investment and operational decisions. ${ }^{36}$

34. See Avinash K. Dixit \& Robert S. Pindyck, Investment Under UncerTAINTY (Princeton Univ. Press 1994) (discussing benefits of delaying uncertain investments).

35. See generally Luis M. Abadie \& José M. Chamorro, Valuation of Energy Investments as Real Options: The Case of an Integrated Gasification Combined Cycle Power Plant (2005), available at http://www.realoptions.org/papers2005/Abadie_IGCC3101 .pdf (discussing valuation of options stemming from flexibility in Integrated Gasification Combined Cycle Power Plant); Richard de Neufville, Real Options: Dealing with Uncertainty in Systems Planning and Design, 4 INTEGRATEd Assessment 26 (2003), available at http://ardent.mit.edu/real_options/Real_opts_papers/delftpaperpub lication.pdf (analyzing wide range of applications of analysis of real options, using documented cases in many fields of engineering); Tao Wang \& Richard de Neufville, Identification of Real Options "in" Projects (2006), available at http://ardent.mit .edu/real_options/Real_opts_papers/Identification\%20of\%20Real\%200ption\% 20in\%20Projects\%20INCOSE.pdf (reviewing sources of flexibility in energy projects).

36. Frank Felder, Integrating Financial Theory and Methods in Electricity Resource Planning, 24 Energy PoL'y 149, 149-54 (1996) (identifying benefits of determining optimal flexibility for individual energy projects). 


\section{The Global Energy System is Interconnected}

The GES is interconnected to other CLIOS systems such as transportation, the global climate system, communications, banking and finance, health services, and water and security. The importance of some of these interconnections are illustrated during electricity blackouts that shutdown transportation, water, and financial systems. IEA, among others, emphasizes the large and increasing amounts of water that is required for energy production, such as for shale natural gas. ${ }^{37}$

Understanding the costs and benefits of energy projects and who bears those costs and who benefits from them is critical in designing and implementing effective mitigation proposals. Energy projects result in both benefits and costs that accrue and are borne by society, but in many cases, not by the investors and direct users. Negative externalities such as environmental emissions are an example, and include sulfur dioxide, nitrogen oxide, mercury, carbon dioxide, thermal discharges, and solid waste products, among others. ${ }^{38}$ The electric power system is a network with AC power flows on one part of the grid impacting flows on other parts. Generation capacity is a positive externality as more capacity reduces the loss of load probability for the system, which benefits all users of the grid, not just the generation owner and its buyer. ${ }^{39}$ The cost of interruption of electric service in the United States is estimated on the order of twenty-five billion to one hundred billion dollars a year and is an example in which the electricity sector bears the costs of reliability but society in general bears the costs of unreliability. 40

\section{E. The Global Energy System is a Sociotechnical System}

The term "sociotechnical" emphasizes that a CLIOS system is not just a technical system, such as a complex computer system, or solely a social system, in which technology is not a critical considera-

37. See World Energy Outlook 2012 Factsheet, supra note 3, at 1, 6.

38. Anthony D. Owen, Renewable Energy: Externality Costs as Market Barriers, 34 ENERGY POL'y 632, 635-38 (2006), available at http://www.ceem.unsw.edu.au/sites/ default/files/uploads/publications/MarketBarriers.pdf (assessing externalities of power generation).

39. See Adam B. Jaffe \& Frank Felder, Should Electricity Markets Have a Capacity Requirement: If So, How Should it be Priced?, 9 ELEctr. J. 52 (Dec. 1996) (discussing positive externalities associated with electricity market capacities).

40. Joseph Eto et al., Scoping Study on Trends in the Economic Value of EleCtRICITY RELIABILITY TO THE U.S. ECONOMY 15-16 (Lawrence Berkley National Laboratory 2001), available at http://www.osti.gov/bridge/servlets/purl/787133$3 \mathrm{Nphiw} /$ nativ e/787133.pdf (discussing cost of interruption of electrical service). 
tion. ${ }^{41}$ Energy policies and plans produce merit goods, goods that are of vital importance to human wellbeing and therefore are of critical political and social importance. As a result, mitigation policies have an immense political dimension requiring that the political and policymaking process must be considered in addition to the critically important technical and economic issues. This applies even in the case of wholesale electricity markets causing challenges in aligning these markets with broader public policies such as climate mitigation. ${ }^{42}$

The term "open" means that the GES explicitly includes social, political, and economic aspects and not just technical or engineering characteristics. In the 2008 paper A Framework for Evaluation of Energy Policy Proposals, Felder presents a high-level depiction of the GES. ${ }^{43}$ The physical system is enclosed within the institutional sphere that organizes, regulates, invests in, operates, establishes markets, and otherwise directly influences components of the world's physical energy system. Two-way arrows between the physical system and the institutional sphere indicate that there are both positive and negative feedbacks between these two elements. Encompassing the institutional sphere is the social and political context. Positive and negative feedbacks exist between both the social and political context and the institutional sphere. The feedbacks include communication and control signals among these three levels.

Climate change mitigation is an important, perhaps even the most important, energy policy and planning goal, but it is certainly not the only one. Many of the definitions of sustainability encompass economic, environmental, and social goals, and even all of human values. Energy proposals and plans attempt to advance many different objectives, ${ }^{44}$ although some advocate using sustainability as an organizing principle for CLIOS systems. ${ }^{45}$ Three

41. CLIOS Process, supra note 29, at 7 (defining primary characteristics of CLIOS Systems).

42. See Frank A. Felder, Watching the ISO Watchman, 25 Electr. J. 24 (Dec. 2012) (discussing energy policy considerations).

43. See A Framework for Evaluation of Energy Policy Proposals, supra note 14, at 488 (depicting World Energy System and how feedback flows between spheres).

44. See Felder, Andrews, \& Hulkower, supra note 2, at 31-62; see also Hatice Tekiner, David W. Coit \& Frank Felder, Multi-Period Multi-Objective Electricity Generation Expansion Planning Problem with Monte-Carlo Simulation, 80 ELEC. Power Sys. REs. 1394, 1394-1405 (2010) (detailing new approach to electricity generation expansion problem).

45. See Joel Cutcher-Gershenfeld et al., Sustainability as an Organizing Design Principle for Large-Scale Engineering Systems 1-46 (Engineering Systems Monograph 2004), available at http://esd.mit.edu/symposium/pdfs/mono 
broad energy planning and policy substantive objectives that are commonly articulated are economic, environmental, and security, and each of these broad objectives contains numerous subordinate objectives. In addition, there are process objectives such as public input and acceptability that are also important. ${ }^{46}$

Within these three goals are many subservient goals, and not surprisingly different stakeholders place different levels of importance on these three major goals and the subservient goals. Furthermore, stakeholders may not even agree on a listing of subservient goals even if they were to agree upon the three major goals. Stakeholders may also behave strategically by not being completely forthright about their values and objectives. For example, a group of stakeholders may overemphasize the value it places on a particular objective in order to try to achieve a compromise closer to its desired position.

Due to the sociotechnical nature of the GES and its provision of merit goods, political institutions and processes are part of the GES institutional sphere. Political time horizons tend to be extremely short-term compared to the lifetimes of components of the GES. The large inertia in the GES makes it difficult for politicians to achieve meaningful improvements within their time horizon. In addition, regulatory and policy processes have their own inertia. ${ }^{47}$ Once a particular policy or plan has been adopted, path dependency, incrementalism, and inertia become issues. Resource constraints restrict the availability and processing of information by particular decision makers in the regulatory process, and this leads to issues such as path dependency, switching costs, and incrementalism. ${ }^{48}$ The effect is that even though the new path would deliver better results, an existing regulatory path is more likely to be

graph/sustainability.pdf (making normative argument that sustainability should be core, overarching principle in design of complex engineering systems).

46. See generally Felder, Andrews, \& Hulkower, supra note 2, at 31-62 (analyzing public input and acceptability).

47. Elizabeth Kirk, Alison Reeves, \& Kirsty L. Blackstock, Path Dependency and the Implementation of Environmental Regulation, 25 Env't \& Planning C: Gov't \& PoL'y 250, 250-68 (2007) [hereinafter Path Dependency] (describing implementation of regulations); Mort Webster, Incorporating Path Dependency into Decision-Analytic Methods: An Application to Global Climate-Change Policy, 5 Decision AnAlysis 60, 60-75 (2008), available at http://globalchange.mit.edu/files/document/MITJPSP GC_Reprint08-23.pdf.

48. Path Dependency, supra note 47, at 250-68 (analyzing effects of resource constraints on decision-making). 
followed than the new path. ${ }^{49}$ Thus, institutional change needs to occur as part of policy change. ${ }^{50}$

These policy and planning processes are intricate, intertwined, and extensive. In the case of New Jersey's energy master plan, there were on the order of five hundred stakeholders involved in its formulation. ${ }^{51}$ Also consider the U.S. electric power sector. Local, state, regional, and federal agencies have various types of authority over the industry from siting of facilities, wholesale market design, and transmission and retail rate determinations. In addition, numerous stakeholders have important interests as evidenced by the numerous customers of Independent System Operators (ISOs), entities that operate parts of the grid and administer wholesale electricity markets in much of the United States. The ISO governance process involves hundreds of actors, a hierarchy of committees, and multiple steps even before consideration by its regulator, the U.S. Federal Energy Regulatory Commission. At the global level, the United Nations Conference on Environment and Development (UNCED), held in Rio de Janeiro from June 3-14, 1992, had 172 governments attending along with approximately 2,400 representatives of non-government organizations (NGOs) and seventeen thousand people participating in the parallel NGO forum. ${ }^{52}$

Given the range and likely substantial value of mitigation options, it is unclear whether in practice planning processes involving stakeholders improve or reduce the ability to exercise options or if, and how, they could be designed to enhance the ability to create and exercise these options. For example, typically these processes require transparent decision-making and involvement of stakeholders. It is not known what conditions and types of public policy processes would result in appropriately implementing real options. For strategic negotiation reasons, some stakeholders may intentionally discount the value of flexibility in order to foreclose the consideration of options that they find undesirable. On the other hand, having large numbers and diverse stakeholders involved in a process may improve the identification of options than would occur otherwise, as discussed by de Neufville, who argues, in the context

49. Id.

50. Id.

51. Frank Felder, Nancy Mantell, Nora Lovrien Buehler, \& Andrew Cottrell, Energy Master Planning: The Case of New Jersey, Environmentalism: ENVIronmental. Strategies and Environmental Sustainability, 41, 41-72 (Elias Kahraman \& Ahmed Baig eds., Nova Publishers 2009) (presenting New Jersey's energy master plan case to show intricacies of policy and planning processes).

52. See Earth Summit, UNITED Nations (last visited Nov. 10, 2013), http://www .un.org/geninfo/bp/enviro.html. 
of projects internal to company, for the need to assemble representatives of various groups to implement real options. ${ }^{53}$

Some regulatory policies discourage options with "used and useful" tests. In regulated portions of the energy industry (e.g., transmission and distribution of electricity and natural gas transportation), regulatory policies may not allow or limit the recovery of investments that promote flexibility if those investments are never used, for example those associated with unexercised options. ${ }^{54}$ Furthermore, many changes in energy policy require legislative action or regulatory proceedings, which involve stakeholder and public input. In some cases, it may be difficult to execute an option, for example, the option to terminate the development of a project, because the project creates constituencies that benefit from the project's continued development and thereby oppose its termination.

\section{Conclusion}

Effective climate change mitigation will require the stabilization of greenhouse gas emissions, and if this can occur with a minimal increase in global average temperature, such stabilization needs to occur soon. Stabilization, whether sooner or later, requires that sources and sinks of greenhouse gases be in equilibrium, which roughly corresponds to at least a sixty percent reduction in greenhouse gas emissions at today's levels. The GES is a useful, but not necessarily the only, framework to understand climate change mitigation policies and proposals. The GES is a largescale system in which no single, carbon-free, or scalable technology exists that would stabilize greenhouse gas emissions in the relatively near future. It is an interconnected and open system, providing vital services in and of itself, but also to other complex systems such as transportation, communication, water, and security. The GES also reflects our fundamental human values and thus is a point of negotiation and contention among numerous stakeholders across multiple jurisdictional boundaries. Although specific policy implications of the GES in the context of climate mitigation are alluded to, but not discussed in this paper, mitigation policies need to be scalable, overcome the inertia of the GES, be able to anticipate and respond to unforeseen outcomes, and integrate technical, eco-

53. de Neufville, Real Options: Dealing with Uncertainty in Systems Planning and Design, supra note 35 , at 26 (suggesting possible advantages of involving more stakeholders).

54. William J. Baumol \& Gregory Sidak, The Pig in the Python: Is Lumpy Capacity Investment Used and Useful?, 23 ENERGY L.J. 383, 383-99 (2002) (noting show some regulatory policies discourage "used and useful" test). 
nomic, and political factors across multiple jurisdictional boundaries that not only address mitigation, but other important substantive and process objectives.

\section{REFERENCES}

1. Dunbar P. Birnie III, Solar-to-Vehicle (S2V) Systems for Powering Commuters of the Future, 186 J. POWER SOuRcEs 539 (2009).

2. Frank Felder, Nuclear Power in the Second Obama Administration, 26 ELECTR. J. 25-31 (March 2013).

3. Frank Felder, The Evolution of Demand-Side Management in the U.S., in Energy Efficiency: Towards the End of Demand GrowTH, 179, 179-200 (Fereidoon P. Sioshansi ed., Elsevier Press 1st ed. 2013).

4. Frank Felder \& Attila Hajos, Using Restructured Electricity Markets in the Hydrogen Transition: The PJM Case, 94 PROCEEDINGS OF THE IEEE (Special Issue) 1864, 1864-79 (2006).

5. Frank Felder \& Ruthanne Haut, Balancing Alternatives and Avoiding False Dichotomies to Make Informed U.S. Electricity Policy, 41 Pol.'y SCI. 165, 165-80 (2008).

6. Int'l Energy Agency, World Energy Outlook 2012 (2012).

7. Judson Jaffe \& Robert N. Stavins, On the Value of Formal Assessment of Uncertainty in Regulatory Analysis, 1 REG. \& GOVERNANCE 154, 154-71 (2007), available at http://www.hks.harvard.edu/ fs/rstavins/Papers/Jaffe_\&_Stavins_Uncertainty_in_RIAs_in_ Regulation_\&_Governance.pdf.

8. Afzal S. Siddigui, Chris Marnay, \& Ryan H. Wiser, Real Options Valuation of U.S. Federal Renewable Energy Research, Development, Demonstration, and Deployment (2005), available at http://emp.lbl.gov/sites/all/files/REPORT \%20lbnl\%20-\%2058000.pdf.

9. Robert H. Socolow \& Stephen W. Pacala, A Plan to Keep Carbon in Check, 295 Scr. AM. 50, $50-57$ (2006), available at http://cmi .princeton.edu/resources/pdfs/carbon_plan.pdf. 